\title{
Near-Peer Teaching Outreach Programs to Increase Minority Physician Recruitment
}

\author{
Wendy F. Linderman, MD ${ }^{1}$ Nicholas Apostolopoulos, MD ${ }^{1}$ Anand D. Gopal, MD \\ John A. Encandela, PhD ${ }^{3,4}$ Christopher C. Teng, MD ${ }^{1}$ Kristen H. Nwanyanwu, MD, MBA ${ }^{1}$ \\ Susan H. Forster, MD ${ }^{1}$
}

1 Department of Ophthalmology and Visual Science, Yale University

School of Medicine, New Haven, Connecticut

2 Yale University School of Medicine, New Haven, Connecticut

${ }^{3}$ Teaching and Learning Center, Yale School of Medicine, New Haven,

Connecticut

${ }^{4}$ Department of Psychiatry, Yale School of Medicine, New Haven,

Connecticut

J Acad Ophthalmol 2018;10:e122-e126.

\author{
Address for correspondence Susan H. Forster, MD, Department of \\ Ophthalmology and Visual Science, Yale University School of \\ Medicine, 40 Temple Street, New Haven, CT 06510 \\ (e-mail: susan.forster@yale.edu).
}

Abstract

\section{Keywords}

- near-peer teaching

- outreach

- minority students

- inner city

- physician recruitment
Problem Health disparities among racial and ethnic groups exist in the United States despite improvements in health status and access to care. These inequalities may be reduced by increasing minority physician recruitment; however, how best to recruit these physicians remains unclear.

Approach Near-peer teachers are not professionally trained, but have recently learned material that they themselves teach. Near-peer teaching in minority student outreach programs may be effective in increasing minority physician recruitment. The authors used a near-peer teaching model to promote interest in medicine, specifically ophthalmology, as a potential career path for both volunteer near-peer teachers and minority high school students participating in an educational outreach program. Twenty-one college and graduate-school near-peer teachers of various racial and ethnic backgrounds participated to teach 31 inner-city high school students. The program was evaluated using pre- and posttest surveys assessing students' knowledge about and interest in science, medicine, and ophthalmology; analysis used pairwise $t$-test comparisons. Qualitative responses and an end-of-training survey also assessed students' and near-peer teachers' satisfaction with the program and perceptions about medicine as a career.

Outcomes Students' knowledge about and interest in medicine and ophthalmology increased significantly after participation. Near-peer teachers agreed that teaching in the program was beneficial to their careers and made it more likely that they would enter medicine and ophthalmology.

Next Steps The authors will track the near-peer teachers' career paths and, in the next iteration, will increase the number of program days. This intervention may serve as a model for outreach for other specialties beyond ophthalmology.

\section{Problem}

Health disparities between populations remain prevalent in the United States, notably among African American and
Hispanic populations compared with Caucasians. ${ }^{1}$ Although life expectancy and overall health of the U.S. population have improved, African Americans and other minorities continue to have higher morbidity and mortality than received

March 10, 2018

accepted

June 18, 2018
DOI https://doi.org/

10.1055/s-0038-1667202.

ISSN $2475-4757$.
Copyright $\odot 2018$ by Thieme Medical

Publishers, Inc., 333 Seventh Avenue,

New York, NY 10001, USA

Tel: +1(212) 584-4662.
License terms

(이 (1) $\Theta \circledast$ 
Caucasians from conditions such as stroke, heart disease, and diabetes mellitus. ${ }^{1}$ Minority populations also have higher visual morbidity from glaucoma and diabetic retinopathy. ${ }^{2,3}$ Some of these differences may be attributable to patient risk factors, such as differences in genetics or nutrition. However, studies have shown that racial and ethnic minorities have less access to regular health care than their white counterparts. In rural areas, for example, the increase in the number of rural health clinics and Federally Qualified Health Centers between 2000 and 2011 in a given area was inversely related to the percentage of minority patients living in the area. ${ }^{4}$

Research suggests that one potential solution to addressing health disparities is to increase the number of minority physicians in the United States. ${ }^{5}$ Minority physicians may be more likely to enter primary care specialties and practice in rural/ underserved areas where need is the greatest. ${ }^{5}$ Additionally, evidence suggests that increasing the number of minority trainees in medical schools can increase cultural competence and sensitivity of the entire student body, teaching them to better care for patients of different races and ethnicities. ${ }^{5}$ It is thus important to increase recruitment of minority students to medical fields. Doing so can be a challenge, as a disproportionate number of minority students grow up in educational environments that lack resources and role models with whom they can identify. ${ }^{6}$

Pipeline programs to increase exposure to science, technology, engineering, and mathematics (STEM) careers for minority populations have become a common initiative to increase minority physician recruitment. ${ }^{7}$ We believe that the efficacy of these pipeline programs can be improved by increasing utilization of near-peer teaching. Near-peer teachers are not professional teachers and have recently learned the material that they themselves are teaching. ${ }^{8}$ Studies demonstrate that students find it easier to learn from near-peers, who, as a result of having recently learned the material, may be more sensitive to some of the barriers learners need to overcome. ${ }^{9}$ Students also express feeling better able to communicate with near-peers compared with older mentors. ${ }^{9}$ Studies have also shown that tutors in nearpeer teaching programs feel they develop professional attributes important to their future careers, including teaching/feedback techniques, leadership qualities, and ability to admit uncertainty. ${ }^{9,10}$ Near-peer teachers believe that their understanding of content is improved by teaching others. ${ }^{10}$ Thus far, near-peer teaching has been implemented most robustly in the medical school setting, with upperclassmen medical students teaching lowerclassmen medical students. There is little in the literature about nearpeer teaching between medical/graduate students, undergraduate students, and high school students. We hoped that creating a near-peer teaching experience would raise awareness of medicine and specifically ophthalmology as potential career paths for the high school students. We also aimed to increase the near-peer teachers' knowledge base of ophthalmology and eye health, as well as their enthusiasm for teaching and pursuing ophthalmology as a career path.

\section{Approach}

We developed an educational initiative comprising a day of ophthalmology outreach for minority students from New Haven public high schools. The high school students were participants of the Yale University Pathways to Science program, which aims to increase exposure to STEM fields through lectures and hands-on experiences at Yale University. Objectives were to: (1) model near-peer teaching across several levels of training; (2) increase students' knowledge of and interest in ophthalmology and medicine as a possible career goal; and (3) increase near-peer teachers' consideration of ophthalmology or another area of health care as a career path.

In our model, 21 volunteers from Yale University's undergraduate, graduate, and professional schools from a variety of ethnic backgrounds including African American, Native American, Chinese, South Asian, and Caucasian were trained to be near-peer teachers. This group consisted of nine undergraduates, nine medical students, one public health student, one nursing postgraduate fellow, and one ophthalmology resident. Each near-peer teacher was assigned to one of three stations and attended training for the assigned station. Training was provided by ophthalmology faculty, residents, and senior medical students. Only the faculty, three senior medical students, and the ophthalmology resident had prior exposure to the material they would be teaching before the training sessions. The other near-peer teachers had not been previously exposed to the material. A senior faculty member developed the curriculum that would be used at all three stations and trained the near-peer teachers for their station with the help of the three senior medical students, who were the leaders at their respective stations. The near-peer teachers' training also included techniques on how to best engage high school students.

The educational outreach day started with introductory remarks and a welcome by the Pathways to Science organizer, followed by a talk by a minority faculty member about his/her path to a career as an academic retinal surgeon, with an emphasis on resilience, the challenges of perceived failures along the way, and coping with setbacks while continuing to pursue her/her career goals. After the presentation, the students were divided into three groups. Each group rotated through three 30-minute stations. Each station focused on a different aspect of ophthalmology with hands-on experience (see - Table 1 for description of each station.) At all three stations, senior medical students assisted near-peer teachers by answering student questions that the near-peers may not have been able to answer. Additionally, the curriculum developer and an additional faculty member were available to the senior medical students if they needed support. Following rotation through all three stations, students returned to the large group space where a panel discussion led by the four graduate students from the Yale University League of Black Scientists focused on each panelist's journey to graduate school in science. The panelists also answered questions that the students had written anonymously prior to the session. All near-peer teacher participants had lunch with the students, after which a brief wrap-up ended the day. 
Table 1 Curriculum content: stations in which students rotate

\begin{tabular}{|l|l|l|}
\hline Station \# & Activity & Intended lessons learned \\
\hline 1 & $\begin{array}{l}\text { Each student dissects a cow's eye (1 near-peer tea- } \\
\text { cher:2 students) }\end{array}$ & $\begin{array}{l}\text { Learn major structures of the eye and their functions } \\
\text { with regard to vision }\end{array}$ \\
\hline 2 & $\begin{array}{l}\text { Introduction to and use of slit lamp (1 near-peer } \\
\text { teacher:4 students); each student practices on fellow } \\
\text { students and views conjunctival vessels, corneal layers, } \\
\text { and crypts within the iris }\end{array}$ & $\begin{array}{l}\text { Learn value of slit lamp in identifying healthy and } \\
\text { pathological eye structures; learn basis of how slit lamp } \\
\text { operates, including how slit beam allows for estima- } \\
\text { tion of depth to examine different parts of the eye }\end{array}$ \\
\hline 3 & $\begin{array}{l}\text { Use iPad app (EyeSim, authored by Dr. Anuradha } \\
\text { Khanna of Loyola University Medical Center) and } \\
\text { prisms to examine eye movement and pathology that } \\
\text { cause eye misalignment and double vision (1 near-peer } \\
\text { teacher:3 students); also, senior medical student leads } \\
\text { students in interaction with a three-dimensional virtual } \\
\text { reality version of the iPad app with holographic display } \\
\text { to further display eye movement pathology }\end{array}$ & $\begin{array}{l}\text { Explore extraocular muscles of the eye and learn how } \\
\text { each monscle moves the eye and the importance of } \\
\text { synchonization to allow eyes to work together for } \\
\text { binocular vision; understand concept of double vision }\end{array}$ \\
\hline
\end{tabular}

To evaluate attainment of our desired outcomes and obtain feedback on the educational activities, we administered a pre- and postsurvey to all high school participants. Institutional review board approval was not needed as the survey was used to elicit feedback an educational intervention. The survey contained: multiple-choice questions assessing knowledge; Likert-style questions assessing student interest in science, medicine, and ophthalmology; and qualitative questions assessing student perceptions and experiences with the training. Quantitative data were analyzed using descriptive statistics and pairwise $t$-tests to compare differences in knowledge and interest levels before and after the training. Qualitative analysis was conducted by independent coding and consensus sessions among the authors to determine thematic qualitative findings. Near-peer teachers completed a postsurvey assessing the impact that participating in the program had on their future career goals. Qualitative analysis, using the above approach, was completed on these survey responses.

\section{Outcomes}

Thirty-one high school students participated in the outreach program and 27 completed the pre/postsurveys. Participant demographics are listed in - Table 2.

Table 2 Demographics of high school participants

\begin{tabular}{|l|l|}
\hline \multicolumn{2}{|l|}{ Sex } \\
\hline Male & 10 \\
\hline Female & 17 \\
\hline Grade & 3 \\
\hline 9th & 12 \\
\hline 10th & 8 \\
\hline 11th & 4 \\
\hline 12th & \\
\hline
\end{tabular}

There was a significant increase in average number of correct responses to knowledge assessment questions, from 2.3 on the presurvey to 5.4 ( $p<0.0001)$ on postsurvey at the end of the day (-Fig. 1).

Average interest in the eye increased significantly from pre- to posttest ( 3.1 to 3.5 on a 5-point Likert scale in which 5 was the most desirable response; $p=0.037$ ). Average interest in ophthalmology increased significantly from 2.6 to 3.1 $(p=0.043)$. Average confidence identifying eye structures increased significantly from 2.4 to 3.7 ( $p<0.0001$ ). Average interest in careers in science and medicine did not increase significantly (-Fig. 2).

From a qualitative standpoint, students expressed their enjoyment of the day and the utility of having near-peer teachers. These comments are representative:

- "My favorite part was meeting all the students here at Yale."

- "I actually want to study the eye now."

- "I liked that it was not too awkward."

Among the near-peer teachers, postsurvey qualitative analysis demonstrated themes of learning how to communicate difficult concepts to high-schoolers. For example, teachers wrote:

- “Teaching helped me to learn different strategies for explaining dense and difficult material to younger or less knowledgeable students."

- "You taught me to keep asking questions of the students in order to let them keep thinking."

Teachers also cited the outreach day as a "valuable opportunity to connect with students and give them advice on school/pursuing a career in science."

Beyond the benefits gained from learning to teach to nearpeers, teachers also expressed the benefits of receiving increased exposure to the fields of medicine and ophthalmology. Respondents wrote:

- "Met a lot of new ophthalmologists and got exposed to teaching in the field." 


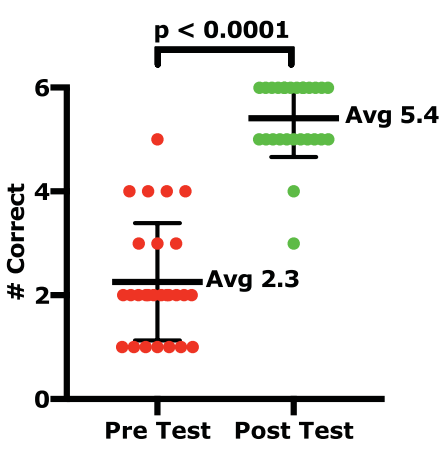

Fig. 1 Number of questions answered correctly by students.

- "I learned how to use the slit lamp which was very cool, and I got to learn about what it's like to be a medical student at Yale."

- "I appreciated the time spent to train me on how to dissect the cow eyes."

- (From a Chinese exchange student): "The best achievement of this activity for me is [that it] drives me [to think] about how to inspire Chinese high school students to consider medicine and science as a career path."

All undergraduate and graduate student teachers who participated in the outreach day agreed or strongly agreed with the following statements:

- "I am more likely to consider a career in medicine or ophthalmology after teaching during outreach day."

- "Teaching during the ophthalmology outreach day helped me to envision myself in a career in medicine or ophthalmology."

Medical students tended to agree that teaching in the program helped them envision how medical education would fit into their future careers and made them more likely to consider careers in ophthalmology.
* No significant difference between

average number answered correctly by girls and boys on pre- or post-test.

\section{Next Steps}

We demonstrated achievement of desired outcomes for both high school students and near-peer teachers. The hands-on experience and direct engagement of students with nearpeer teachers allowed high school students to receive valuable mentorship from those who were in their position not long ago. The diverse backgrounds of the near-peer teachers served as a venue for the high school students to connect with the teachers and imagine themselves as part of the medical and scientific community. Beyond the positive impact of the mentorship provided by the near-peer teachers, our results indicate that near-peer teaching show promise as an effective method for student learning and for inspiring both teachers and learners to consider careers in medicine or a specific specialty. Given the positive outcomes, we believe this model may be effective in increasing minority physician recruitment. A limitation of our assessment was the small sample size of high school students and nearpeer teachers who participated. However, our goal was to first demonstrate the approach with this small number, as well as to collect preliminary information about achievement of outcomes. In this sense, our approach was

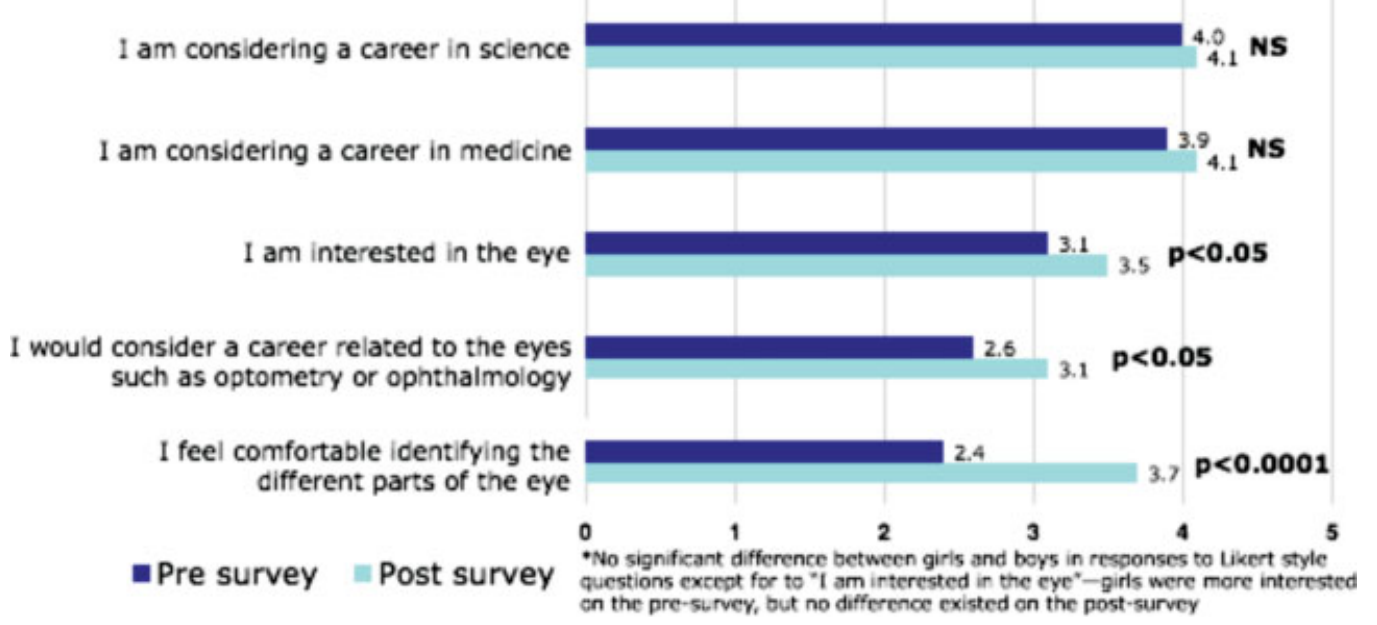

Fig. 2 Average response to Likert-style questions before and after outreach day. 
exploratory, with the intent of expanding the program in the next iteration.

We plan to continue this program on an annual basis and expand it to include a summer course on optics and ophthalmology over several days. These expanded programs will offer an opportunity for inner city high school students to increase their knowledge in applied science, optics, and ophthalmology and offer them greater contact with their near-peer teachers. Although there was not a significant increase in interest in science and medicine following our program, our data may have been limited by self-selection of the students participating in the Yale University Pathways to Science program as these students likely already have interest in science and medicine. In the future, we plan to incorporate another station involving a case of a patient who is blind so that the high school students can experience patient interaction. We also plan to more thoroughly evaluate the impact of the program on the nearpeer teachers and their career path decisions. In addition to the possibility of attracting future physicians to the field of ophthalmology, we believe that our program may be a model for other medical specialties who may want to similarly increase numbers of minority physicians.

\section{Conflict of Interest}

None declared.

\section{Acknowledgments}

Thanks to Judy Spak in the Yale School of Medicine Cushing/Whitney library for assistance with literature search. This work was previously presented at the Yale School of Medicine Medical Education Day in May 2017 and the Association of University Professors in Ophthalmology Educating the Educators Meeting in January 2018.

\section{References}

1 National Center for Health Statistics. Health, United States, 2016: With Chartbook on Long-term Trends in Health. Hyattsville, MD: National Center for Health Statistics; 2017

2 Glaucoma Research Foundation. African Americans and Glaucoma. Available at: http://www.glaucoma.org/glaucoma/african-americans-and-glaucoma.php. Accessed July 31, 2017

3 Centers for Disease Control. Diabetic Retinopathy. Available at: https://www.cdc.gov/visionhealth/pdf/factsheet.pdf. Accessed July 31, 2017

4 Koppaka V, Chen Y, Mehta G, et al. ALDH3A1 plays a functional role in maintenance of corneal epithelial homeostasis. PLoS One 2016;11(01):e0146433

5 Kington R, Tisnado D, Carlisle DM. Increasing racial and ethnic diversity among physicians: an intervention to address health disparities? In: Smedley BD, Stith AY, Colburn L, et al; The Right Thing to Do, The Smart Thing to Do: Enhancing Diversity in the Health Professions: Summary of the Symposium on Diversity in Health Professions in Honor of Herbert W. Nickens, M.D. Washington, DC: National Academies Press; 2001:57-90

6 Rohrbaugh MC, Corces VG. Opening pathways for underrepresented high school students to biomedical research careers: the Emory University RISE program. Genetics 2011;189(04):1135-1143

7 Fincher RM, Sykes-Brown W, Allen-Noble R. Health science learning academy: a successful "pipeline" educational program for high school students. Acad Med 2002;77(07):737-738

8 Topping K. Trends in peer learning. Educ Psychol 2005;25(06): 631-645

9 Tenenbaum LS, Anderson MK, Jett M, Yourick DL. An innovative near-peer mentoring model for undergraduate and secondary students: STEM focus. Innov High Educ 2014;39(05):375-385

10 Burgess A, McGregor D, Mellis C. Medical students as peer tutors: a systematic review. BMC Med Educ 2014;14(01):115 